\title{
Cleaning of first mirrors in ITER by means of radio frequency discharges
}

Leipold, Frank; Reichle, R.; Vorpahl, C.; Mukhin, E. E.; Dmitriev, A. M.; Razdobarin, A. G.; Samsonov, D. S.; Marot, L.; Moser, L.; Steiner, R.

Total number of authors:

11

Published in:

Review of Scientific Instruments

Link to article, DOI:

$10.1063 / 1.4962055$

Publication date:

2016

Document Version

Publisher's PDF, also known as Version of record

Link back to DTU Orbit

Citation (APA):

Leipold, F., Reichle, R., Vorpahl, C., Mukhin, E. E., Dmitriev, A. M., Razdobarin, A. G., Samsonov, D. S., Marot, L., Moser, L., Steiner, R., \& Meyer, E. (2016). Cleaning of first mirrors in ITER by means of radio frequency discharges. Review of Scientific Instruments, 87(11), [11D439]. https://doi.org/10.1063/1.4962055

\section{General rights}

Copyright and moral rights for the publications made accessible in the public portal are retained by the authors and/or other copyright owners and it is a condition of accessing publications that users recognise and abide by the legal requirements associated with these rights.

- Users may download and print one copy of any publication from the public portal for the purpose of private study or research.

- You may not further distribute the material or use it for any profit-making activity or commercial gain

- You may freely distribute the URL identifying the publication in the public portal 


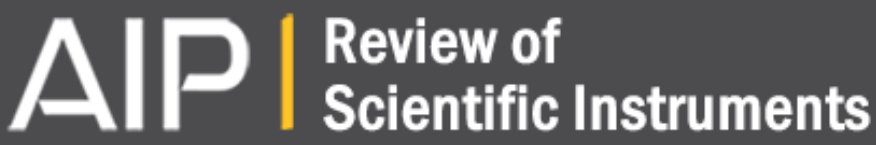

\section{Cleaning of first mirrors in ITER by means of radio frequency discharges}

F. Leipold, R. Reichle, C. Vorpahl, E. E. Mukhin, A. M. Dmitriev, A. G. Razdobarin, D. S. Samsonov, L. Marot

, L. Moser, R. Steiner, and E. Meyer

Citation: Review of Scientific Instruments 87, 11D439 (2016); doi: 10.1063/1.4962055

View online: http://dx.doi.org/10.1063/1.4962055

View Table of Contents: http://scitation.aip.org/content/aip/journal/rsi/87/11? ver=pdfcov

Published by the AIP Publishing

\section{Articles you may be interested in}

Resonant-frequency discharge in a multi-cell radio frequency cavity

J. Appl. Phys. 116, 173301 (2014); 10.1063/1.4900994

Simultaneous imaging/reflectivity measurements to assess diagnostic mirror cleaninga)

Rev. Sci. Instrum. 83, 10D512 (2012); 10.1063/1.4733538

Beryllium deposition on International Thermonuclear Experimental Reactor first mirrors: Layer morphology and influence on mirror reflectivity

J. Appl. Phys. 102, 083302 (2007); 10.1063/1.2798389

First tests of molybdenum mirrors for ITER diagnostics in DIII-D divertor

Rev. Sci. Instrum. 77, 10F126 (2006); 10.1063/1.2336465

Plasma diagnostic tools for optimizing negative hydrogen ion sources

Rev. Sci. Instrum. 77, 03A516 (2006); 10.1063/1.2165769

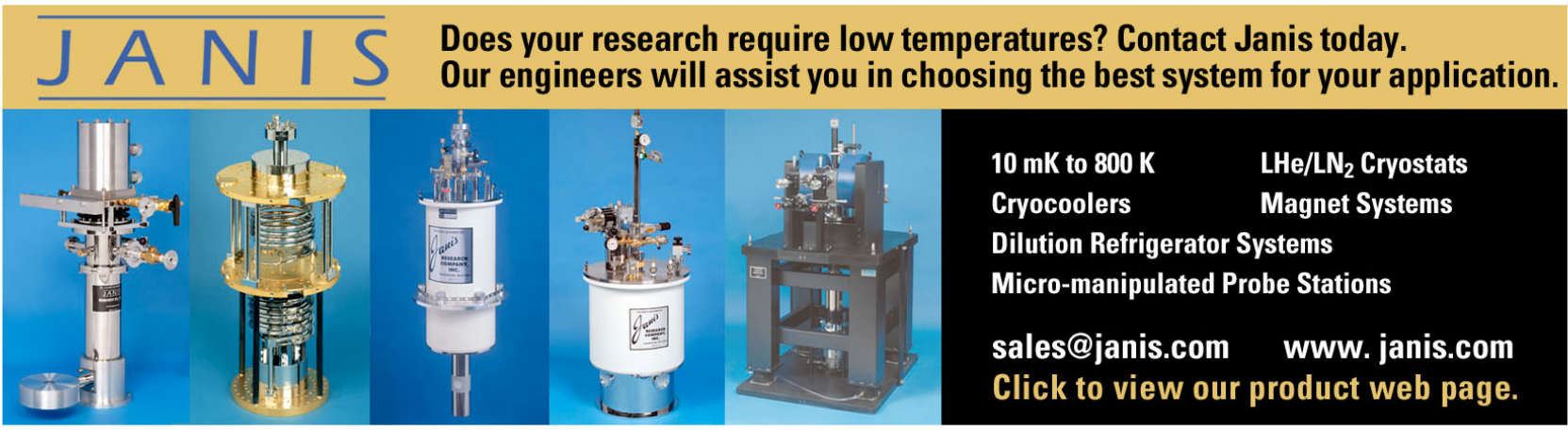




\title{
Cleaning of first mirrors in ITER by means of radio frequency discharges
}

\author{
F. Leipold, ${ }^{1,2, a)}$ R. Reichle, ${ }^{2}$ C. Vorpahl, ${ }^{2}$ E. E. Mukhin, ${ }^{3}$ A. M. Dmitriev, ${ }^{3}$ A. G. Razdobarin, ${ }^{3}$ \\ D. S. Samsonov, ${ }^{3}$ L. Marot, ${ }^{4}$ L. Moser, ${ }^{4}$ R. Steiner, ${ }^{4}$ and E. Meyer ${ }^{4}$ \\ ${ }^{1}$ Department of Physics, Technical University of Denmark, DK-2800 Lyngby, Denmark \\ ${ }^{2}$ ITER Organization, Route de Vinon-sur-Verdon, CS 90 046, 13067 St Paul-lez-Durance, France \\ ${ }^{3}$ Ioffe Institute, Polytechnicheskaya St. 26, St. Petersburg 194021, Russian Federation \\ ${ }^{4}$ Department of Physics, University of Basel, Klingelbergstrasse 82, CH-4056 Basel, Switzerland
}

(Presented 6 June 2016; received 7 June 2016; accepted 14 August 2016; published online 7 September 2016)

\begin{abstract}
First mirrors of optical diagnostics in ITER are subject to charge exchange fluxes of $\mathrm{Be}, \mathrm{W}$, and potentially other elements. This may degrade the optical performance significantly via erosion or deposition. In order to restore reflectivity, cleaning by applying radio frequency (RF) power to the mirror itself and thus creating a discharge in front of the mirror will be used. The plasma generated in front of the mirror surface sputters off deposition, restoring its reflectivity. Although the functionality of such a mirror cleaning technique is proven in laboratory experiments, the technical implementation in ITER revealed obstacles which needs to be overcome: Since the discharge as an RF load in general is not very well matched to the power generator and transmission line, power reflections will occur leading to a thermal load of the cable. Its implementation for ITER requires additional R\&D. This includes the design of mirrors as RF electrodes, as well as feeders and matching networks inside the vacuum vessel. Mitigation solutions will be evaluated and discussed. Furthermore, technical obstacles (i.e., cooling water pipes for the mirrors) need to be solved. Since cooling water lines are usually on ground potential at the feed through of the vacuum vessel, a solution to decouple the ground potential from the mirror would be a major simplification. Such a solution will be presented. Published by AIP Publishing. [http://dx.doi.org/10.1063/1.4962055]
\end{abstract}

\section{INTRODUCTION}

First mirrors (FMs) of numerous optical diagnostics at ITER are subject to deposition or erosion or both during ITER operation. ${ }^{1,2}$ This causes reduction of optical performance of the diagnostic. ${ }^{3}$ In order to prevent or mitigate mirror degradation, the optical quality must be preserved, i.e., by applying a sputter-resistant coating on the reflective surface. ${ }^{4}$ Alternatively, it must be restored periodically during ITER life time by appropriate cleaning techniques. Among several technologies (like laser ablation ${ }^{5}$ or microwave sputtering), radio frequency (RF) plasma sputtering turned out to be the most promising technology for this task. ${ }^{6-8}$ Since plasma sputtering constitutes an erosion, also of the mirrors, appropriate mirror materials have to be chosen. ${ }^{9}$

In order to generate a plasma for sputtering, RF power is applied to the mirror itself, generating a plasma in front of it. The ions in the plasma have the capability to sputter deposits off the mirror surface, recovering the original surface. The backside of the mirror is shielded to inhibit plasma formation there.

Since the ratio of the areas of the mirror to the grounded surface (vacuum vessel) is significantly smaller than unity, a negative bias voltage forms on the mirror if the RF power is capacitively coupled to it. ${ }^{10}$ The bias voltage has an influence

Note: Contributed paper, published as part of the Proceedings of the $21 \mathrm{st}$ Topical Conference on High-Temperature Plasma Diagnostics, Madison, Wisconsin, USA, June 2016.

a)Electronic mail: frank.leipold@iter.org on the ion impinging energy. ${ }^{11}$ However, the bias voltage is affected by the presence of a magnetic field. It is reduced if a magnetic field is present. ${ }^{12}$ At the same time, the magnetic field strongly influences the ion angle and flux spatial distribution. The angle of the magnetic field incidence and size of the mirror can significantly affect the cleaning rate and uniformity. Additional mechanical constraints have to be considered as well. FMs in ITER are subject to heating due to neutron flux and the intense radiation. ${ }^{13}$ In order to dissipate the heat, most FMs are water cooled. An RF driven mirror cleaning system consists of an RF plasma device and the operating regime to achieve efficient cleaning. We want to focus on the RF device only as the device requires engineering $R \& D$. This is due to the fact that (i) a matching network cannot be installed next to the load, (ii) simple components like coils or capacitors cannot be installed close to the load as the environment is under low pressure and the RF carrying components might cause undesired discharges, and (iii) the load has DC connection to the ground (water cooling line) which needs to be considered in the overall RF design. In addition, cables for feed lines inside ITER cannot be freely chosen. Only mineral insulated cables are allowed which makes the device more sensitive to impedance mismatches due to their rather high loss tangent of the insulating material. The discharge is operated in $\mathrm{Ar}$ typically at a pressure between 1 and $10 \mathrm{~Pa}$ and at power settings between 10 and $100 \mathrm{~W}$. The physics of the discharge is described elsewhere and is not subject to this manuscript. Impedance consideration of FMs is done in Section II and a solution is pointed out in Section III. 


\section{REFLECTION OF WAVES}

In general, the impedance of the load (in this case the mirror including plasma) is not even close to the feeder system characteristic impedance (typically $50 \Omega$ ). In order to transform the mirror impedance, a matching network is required. This protects the generator power from being reflected back into the generator. However, power is reflected back and forth in the transmission line between the matching network and mirror. This causes significant losses, exceeding the single pass losses by far in particular in high loss transmission lines like mineral insulated cables.

An example is shown in Fig. 1. The impedances $(f=60 \mathrm{MHz})$ shown were either measured by inserting a directional coupler at the point of interest and measuring forward and reflected wave-voltage including the phase difference or calculated if the point of interest is not accessible. The mirror has an impedance of $Z=4-26 i \Omega$. The mirror was connected via a coaxial transmission line to a feed through of the vacuum vessel (point "C" in Fig. 1). This transmission line was considered loss-less as the dielectric between inner and outer conductors was vacuum. The mirror impedance was transformed to $Z=2.5-10.8 i \Omega$ at point "C." The feed through of the vacuum chamber (point " $\mathrm{C}$ ") was connected via a low loss cable with a length of $2 \mathrm{~m}$ to the output of the matching network (point "B"). The loss of this cable was specified with $0.019 \mathrm{~dB} / \mathrm{m}$ at $60 \mathrm{MHz}$. This means if the cable is used with a matched load, $0.87 \%$ of the power is absorbed by the cable. However, since the cable is connected to an unmatched load, power is reflected between points " $\mathrm{B}$ " and " $\mathrm{C}$ " causing a total loss of $8.5 \%$ (calculation). This is approximately 10 times more than expected by the cable specification. If the transmitted power is high, the loss in the cable can become substantial, causing heating or even destruction of the cable.

Besides heating of the cable, also high currents can cause damage to the cable. This is illustrated in the following example (refer to Fig. 1): The supplied power shall be $200 \mathrm{~W}$. This corresponds to a voltage of $100 \mathrm{~V}$ and a current of $2 \mathrm{~A}$ in a matched condition (Point "A"). At point " $C$," the current was calculated to be $8.5 \mathrm{~A}$ while the voltage was $94 \mathrm{~V}$. The majority of the power is not real power, it is power being reflected back and forth in the cable. Even though this power does

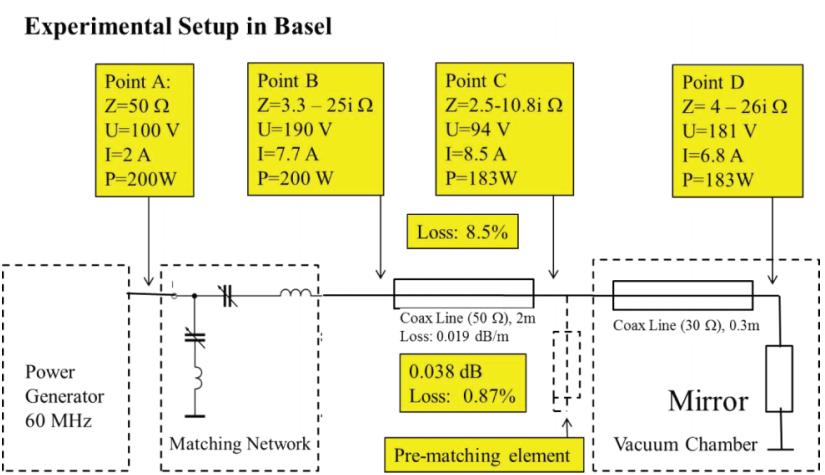

FIG. 1. Block diagram of the experimental setup at Basel University. The indicated power is the real power. Imaginary power is not shown. Voltage and current are absolute values, the phase is not considered. not contribute to the plasma in front of the mirror, the cable between points " $\mathrm{B}$ " and "C" has to take it. As comparison, a current of $8.5 \mathrm{~A}$ in a $50 \Omega$ load corresponds to a power of $3.6 \mathrm{~kW}$. This means that the cable must be capable of handling $3.6 \mathrm{~kW}$, although the useful power is only $200 \mathrm{~W}$. The problem can be mitigated, if pre-matching elements at point "C" are used. Currents into (and from) the matching elements can still be high, but the impedance at point " $\mathrm{C}$ " seen by the transmission line between the matching network and point " $\mathrm{C}$ " is much closer to $50 \Omega$, reducing the losses in the cable.

Pre-matching elements can be capacitors or inductances. This method was employed at a $60 \mathrm{MHz}$ capacitively coupled plasma experiment at the University of Basel. The required power for this discharge for establishing a self-bias of $-270 \mathrm{~V}$ could be reduced from $150 \mathrm{~W}$ to $90 \mathrm{~W}$ by connecting a $77 \mathrm{~cm}$ long open end coaxial transmission line as a pre-matching element at point "C." Severe heating of the feed through and transmission line was avoided by this step. In order to reduce power loss in in-vessel transmission line, the pre-matching element should be located as close as possible to the mirror. In this case the coaxial pre-matching element also becomes in-vessel, and should be designed in a way to avoid plasma formation.

There is no standard procedure as how to achieve impedance matching of an unknown load. This is attributed to the large variety of dimensions of mirrors for different diagnostic systems. Each design has to be analyzed individually, and the best methods of matching have to be determined.

\section{MIRROR COOLING}

Numerous FMs need water cooling. The water cooling lines may pose a difficulty for RF power as they are either on ground potential at the feed through and affect the impedance of the mirror (Fig. 2) or they are electrically insulated through the vacuum vessel as described in Ref. 7.

Several techniques have been considered for mirror cooling: (i) Electrical insulation of the mirror but in good thermal contact with a water cooled surface, (ii) electrical insulation of the cooling water line at the feed through, ${ }^{7}$ and

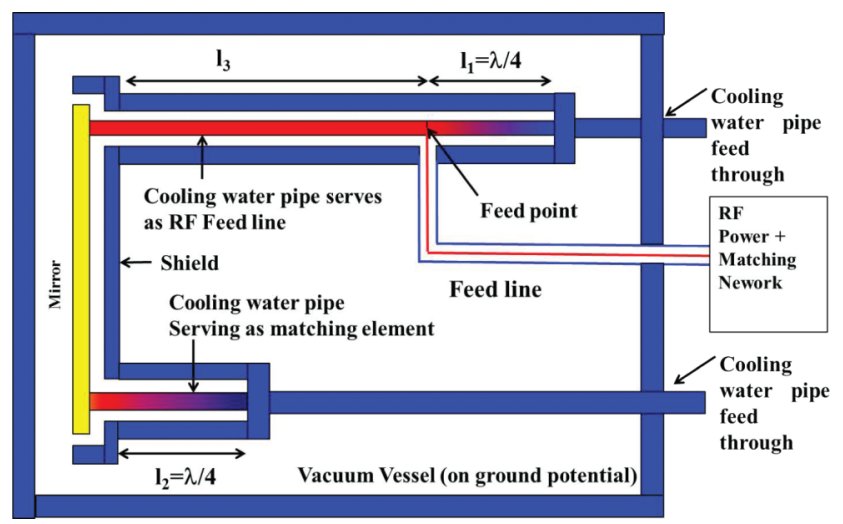

FIG. 2. Schematic of a RF cleaned FM with cooling water lines inside the vacuum vessel. Yellow: mirror, blue: metal parts on ground potential, red: RF potential. The distance between mirror and vacuum vessel is not to scale. 
(iii) integration of the water cooling line into a stop band filter and considering the additional impedance.

Solution (i) has the advantage that the electrical behaviour of the mirror is almost the same as without cooling. The thermal contact is a critical point and efficient cooling of the mirror may be compromised. Solution (ii) has the advantage that the thermal contact is good, but conductivity of the cooling water can lead to unpredicted currents and changes in the overall impedance. This is due to the possible increase of ions in the cooling water, leading to increased conductivity. The water conductivity may affect the bias voltage and consequently the cleaning process. There is also a risk of dissociation of water molecules leading to hazardous gases in the cooling water system. Solution (iii) has the advantage that a good thermal contact is obtained, the cooling water lines can be at ground potential at the feed through. However, there will be no bias on the mirror surface, since the cooling water line forms a DC ground to the mirror. As a consequence, also the ion energy is reduced. ${ }^{12}$ The functionality for case (iii) has also been demonstrated. ${ }^{7}$

In reality, the stop band filter can be designed as shown in Fig. 2. For laboratory experiments, where no water cooling is needed, the cooling water line is represented by the inner conductor of a coaxial cable with an electrical length of $\lambda / 4$. The end of the cable is short circuited with the shielding of the cable, representing the cooling water line going through the closure plate and having an electrical contact to ground.

This is an example, other possibilities exist. Which precise implementation is chosen will depend on the various constraints of system integration. The cooling water line and the shroud around it form a coaxial transmission line up to the feed point to the feed line. Impedance and length can be chosen in such a way that brings the overall impedance at the feed point as close as possible to the desired $50 \Omega$. The water pipe between the feed point and closure plate forms a transmission line which is short circuited at distance of $l_{1}=\lambda / 4$. Therefore, this section has an infinite impedance (ideal case) at the feed point and does not change the overall impedance at the feed point. However, it is a DC short circuit and prevents a DC bias voltage at the mirror.

For an operation frequency of $60 \mathrm{MHz}, \lambda / 4=1.25 \mathrm{~m}$ (if the space between the inner conductor and shroud is vacuum). The other water pipe can be designed as a transmission line as well. The length, $l_{2}$, to the point where the water pipe is connected to ground should be $\lambda / 4$, but it can be adjusted in such a way that it serves as a pre-matching element. In addition, the impedance at the feed point can be manipulated by changing the length $l_{3}$, and the impedance of the corresponding section of the water cooling line in order to move the impedance closer to $50 \Omega$.

This may contribute to a reduction in power loss between the transmission line and matching network as discussed in Section II.

\section{OUTLOOK}

The suitability of the plasma cleaning has been demonstrated in laboratory facilities only. The functionality of the RF device shall be demonstrated on a mock-up of at least one optical ITER diagnostic system. Up to now, there are no specific plans for a mock-up.

\section{ACKNOWLEDGMENTS}

The views and opinions expressed herein do not necessarily reflect those of the ITER Organization.

${ }^{1}$ D. Ivanova, M. Rubel, A. Widdowson, P. Petersson, J. Likonen, L. Marot, E. Alves, A. Garcia-Carrasco, G. Pintsuk, and JET-EFDA Contributors, Phys. Scr. T159, 014011 (2014).

${ }^{2}$ A. Litnovsky, V. S. Voitsenya, A. Costley, A. J. H. Donne, and ITPA Topical Group on Diagnostics, Nucl. Fusion 47, 833 (2007).

${ }^{3}$ L. Marot, E. Meyer, M. Rubel, D. Ivanova, A. Widdowson, J. P. Coad, J. Likonen, A. Hakola, S. Koivuranta, G. De Temmerman et al., J. Nucl. Mater. 438, S1187 (2013).

${ }^{4}$ E. E. Mukhin, V. V. Semenov, A. G. Razdobarin, S. Y. Tolstyakov, M. M. Kochergin, G. S. Kurskiev, K. A. Podushnikova, S. V. Masyukevich, D. A. Kirilenko, A. A. Sitnikova et al., Nucl. Fusion 52, 013017 (2012).

${ }^{5}$ M. Wisse, L. Marot, A. Widdowson, M. Rubel, D. Ivanova, P. Petersson, R. P. Doerner, M. J. Baldwin, J. Likonen, E. Alves et al., Fusion Eng. Des. 89, 122 (2014).

${ }^{6}$ L. Moser, R. Steiner, F. Leipold, R. Reichle, L. Marot, and E. Meyer, J. Nucl. Mater. 463, 940 (2015).

${ }^{7}$ L. Moser, L. Marot, B. Eren, R. Steiner, D. Mathys, F. Leipold, R. Reichle, and E. Meyer, Nucl. Fusion 55, 063020 (2015).

${ }^{8}$ A. G. Razdobarin, A. M. Dmitriev, A. N. Bazhenov, I. M. Bukreev, M. M. Kochergin, A. N. Koval, G. S. Kurskiev, A. E. Litvinov, S. V. Masyukevich, E. E. Mukhin et al., Nucl. Fusion 55, 093022 (2015).

${ }^{9}$ A. Litnovsky, P. Wienhold, V. Philipps, G. Sergienko, O. Schmitz, A. Kirschner, A. Kreter, S. Droste, U. Samm, P. Mertens et al., J. Nucl. Mater. 363, 1395 (2007).

${ }^{10}$ L. Wilken, V. Hoffmann, and K. Wetzig, Spectrochim. Acta, Part B 62, 1085 (2007).

${ }^{11}$ G. De Temmerman, R. A. Pitts, V. S. Voitsenya, L. Marot, G. Veres, M. Maurer, and P. Oelhafen, J. Nucl. Mater. 363, 259 (2007).

${ }^{12}$ A. M. Dmitriev, A. G. Razdobarin, and D. S. Samsonov (unpublished results).

${ }^{13}$ M. Salewski, F. Meo, H. Bindslev, V. Furtula, S. B. Korsholm, B. Lauritzen, F. Leipold, P. K. Michelsen, S. K. Nielsen, and E. Nonbol, Rev. Sci. Instrum. 79, $10 \mathrm{E} 729$ (2008). 